\title{
Power Portfolio Optimization with Traded Contract Products
}

\author{
Yi Sun, Student Member, IEEE, Felix F. Wu, Fellow, IEEE, and Hui Zhou
}

\begin{abstract}
Power sector restructuring has prompted the application of modern portfolio theory among market participants. Much research has been devoted to power portfolio optimization problems. However, the portfolio composition adopted in literature is rather hypothetical than realistic. From an engineering perspective, it is necessary to use real traded contract products to construct the portfolio. In this paper, clarification is made on commonly traded power contracts in the market, followed by a discussion of their pricing schemes. It is emphasized that actively traded electricity futures/forwards and options actually belong to commodity swaps and swaptions respectively. A power portfolio is then constructed for a generation company with these basic power contracts and the spot transaction as well. An optimization model is formulated to solve the asset allocation with Conditional Value at Risk (CVaR) as the risk measure. The viability of the model is tested through a numerical study.
\end{abstract}

Index Terms - Power portfolio, electricity futures, electricity options, commodity swaps, Value at Risk

\section{INTRODUCTION}

Power sector restructuring prompts the industry to operate in a more efficient way, but meanwhile it also brings more risk factors to investors compared with the conventional regulated regime. In order to deal with increased uncertainty, it is necessary for management to apply modern portfolio theory which tells about the method to combine assets and the principle of diversification into their daily operational decisions [1]. In addition, market participants differ in both of their strategic goals and planning horizon, so they need to form tailor-made optimization models for their own portfolio needs.

Power portfolio management considered by a generation company involves optimization at two stages. One is at the capacity planning stage, which aims to optimize the generation mix portfolio. This optimization problem could be solved either at a corporate level or at a country level. The other is at the production stage, which devotes to allocating generation capability among various power supply instruments.

This research is supported by the Research Grant Council of Hong Kong under the grant HKD7186/08E.

Corresponding author: Yi Sun, yisun@hku.hk.

Yi Sun and Felix F. Wu are with the University of Hong Kong, Hong Kong, China. Hui Zhou is with Zhejiang Electric Power Corporation, State Grid, China.
A power portfolio optimization problem possesses its distinct features compared with optimizing other financial portfolios [2]. Firstly, in terms of decision variables, discrete values appear in a power portfolio. This could result from the on/off decisions of generation units, the power amount specified in supply contracts, and pumping levels of pumpedstorage units. Secondly, with respect to constraints, the real time load obligation constraint governs the coordination among different power supply instruments.

Research contributions to the power portfolio optimization problem mainly focus on three aspects including portfolio composition, risk constraints, and computation algorithms. In terms of portfolio composition, various derivative contracts are included into the portfolio [2] [3], and hydro pumped storage plant and combined heat and power (CHP) plant are also added to improve operational flexibility [4] [5]. In terms of risk constraints, the modeling is becoming more sophisticated. Firstly, in order to better identify the price risk, the model for spot price process requires more thoroughness, e.g. price spikes are considered. Secondly, since the planning horizon is relatively long in the power industry, the single period risk management model is doubted for underestimating intermediate risks. Thirdly, normality is gradually recognized as not satisfied with electricity, so people are trying to find substitutes for variance that is used in the conventional Markowitz mean-variance approach. Measures are developed such as semi-variance based risk measure [2], Value at Risk (VaR) and Conditional Value at Risk (CVaR). Fourthly, due to special features of this industry, more risk factors should also be considered, such as the volume risk caused by demand fluctuation or plant outages, see [5]. In terms of computation algorithms, works include the adoption of the scenario tree in time series approximation, the use of stochastic dynamic programming for problem solving, and improvement made on the convergence speed of the solution process [2].

However, there is an overlooked issue with regard to portfolio composition. Investigating those power portfolios in literature, contracts used to construct the portfolio are mostly hypothetical rather than real traded products in the market place. For example, some researchers use single/instantaneous delivery futures/forwards, and some adopt options written on spot electricity or written on single/instantaneous delivery futures/forwards [2] [3]. However, these contracts are not widely traded power contracts. Different from other commodity markets, the futures/forwards widely traded in the power market are actually swaps covering a delivery period 
rather than a single time delivery. Furthermore, because spot electricity is not proper to serve as the underlying of options due to its non-storability, traded electricity options are options written on swaps, i.e. they are swaptions. From an engineering point of view, it is necessary to substitute those unrealistic power contracts with real traded ones in constructing portfolios.

This work tries to optimize a power contract portfolio which is composed of spot electricity, swaps contracts and swaptions contracts. Contents are organized as following: II. Clarification is made on traded electricity contracts and their pricing schemes. III. The portfolio optimization model is formulated. IV. Numerical example is studied with implication explained.

\section{ClARIFICATION ON TRADED CONTRACTS}

\section{A. Electricity futures/forwards contracts}

Clarification is necessary to be made in the first place on electricity futures/forwards contracts. On one hand, electricity futures/forwards contracts are critical risk hedging instruments in a power portfolio. On the other hand, they serve as the underlying of option contracts in the electricity market where spot electricity is not suitable for options being written on.

In equity markets, single/instantaneous delivery forwards/futures contracts are widely traded. The forward price $\mathrm{F}$ is the compounded value of the spot price $\mathrm{S}$ under the risk-neutral measure according to the no-arbitrage principle, i.e. $F=S e^{r(T-t)}$, where $\mathrm{r}$ is the risk-free interest rate and $\mathrm{T}$ is the maturity of the forwards/futures contract. In commodity markets where storable goods are traded, researchers have developed a concept of convenience yield to valid the above no-arbitrage relationship between spot price and forward price. As with oil, this holds as $F=S e^{(r-y)(T-t)}$, where y is the convenience yield net of storage cost. This convenience yield accounts for the benefit of owning the physical commodity rather than a futures contract written on it. Both of the above relationships lead to the convergence of the forward price to the spot price at the maturity of the contract, e.g. $F=S e^{r(T-T)}=S$. However, there is no such convergence of forward prices in the power market.

In the power market, there is no trade on single/instantaneous delivery futures/forwards contracts. In fact, electricity futures/forwards contracts cover different delivery periods, and they are more suitably called electricity swaps. An electricity swap contract is normally settled daily as the difference between the price specified in the swap contract and the daily spot price. It might help make a clearer clarification by looking at the traded products in the market place $^{1}$. At Nord Pool, day and week futures contracts are listed

\footnotetext{
${ }^{1}$ Contracts specifications described in this paper are based on the information provided on the websites of corresponding markets. Further details could be found at www.nordpool.com, www.nymex.com, www.eex.com, and www.aemo.com.au.
}

with horizon of 6 weeks. Settlement of these futures contracts involves both daily mark-to-market settlement in the trading period and a final spot reference settlement in the delivery period. Forward contracts are also listed by Nord Pool covering each calendar month, quarter and year. These forward contracts have no mark-to-market settlement, so settlement is accumulated and realized in the delivery period. See Figure 1 for the trading data of the April-2007 monthly swap at Nord Pool within the two months right before delivery. In the US, PJM daily and monthly futures contracts are listed at New York Mercantile Exchange (NYMEX) for trading, and financial settlement is based on the arithmetic average of the PJM western hub real-time hourly locational marginal price (LMP) provided by PJM Interconnection LLC. In Germany, monthly swaps have the highest liquidity in the European Energy Exchange (EEX) market. At the Australian Energy Market (AEM, the former National Electricity Market) in Australia, forward contracts are called swaps in the overthe-counter (OTC) market and called futures at the Sydney Futures Exchange (SFE). Because of the flow feature of electricity, electricity forward price converges toward the average spot price through the delivery period rather than the spot price at maturity. More specifically, the electricity forward price converges to the risk-adjusted market expectation of the average spot price of the delivery period. It could also be understood as that the underlying asset (price) of electricity forwards is the average spot price of the delivery period. To eliminate ambiguity, we will use the word electricity swaps to represent electricity futures/forwards in the rest part of this paper.

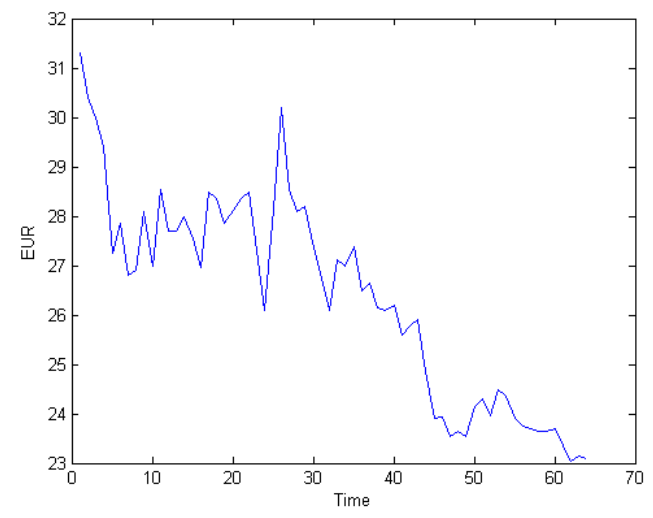

Figure 1 Daily trading data of the April-2007 monthly swap at Nord Pool (Source: Nord Pool, unit: per MWh)

With regard to power swaps pricing, the proposed methodologies in literature fall into two categories, the indirect approach and the direct approach. The indirect approach involves two steps. The first step is to model a forward curve describing the prices of artificial singledelivery forwards over the delivery period. The second step is to model swaps as integrals of such single-delivery forwards. There are two methods to accomplish the first step. One is to start with a spot price model, and then the forward curve is built based on the spot dynamics, see for example [6], [7]. The other is to define the forward curve dynamics as an exogenous 
process, for example using the Heath-Jarrow-Morton (HJM) approach originated in [11], [12]. But these two methods both require smoothing techniques when fitting the model to trading data, see for example [8]. Some researchers try to work out a more realistic forward curve, and their works are also capable to be served as the first step of the indirect approach [9], [10]. In contrary, the direct approach models swap dynamics directly as a stochastic process instead of going via the non-existing single-delivery forwards.. It is inspired from the Brace-Gatarek-Musiela (BGM) market mode [13] which models only the traded contracts. The BGM model is also developed under the HJM framework. It is also convenient to use the swap prices quoted in the market for model calibration. The key to the techniques developed under the HJM framework is that the drift term of the forward rates (or prices) under the risk-neutral measure is uniquely determined by the volatility functions when a number of regularity conditions and the standard no-arbitrage condition are satisfied. In this paper, we adopt the market model proposed by [14].

Considering a swap contract which covers a delivery period $\left[T_{1}, T_{2}\right]$, the dynamics of trading prices $F\left(t, T_{1}, T_{2}\right)$ could be defined as

$d F\left(t, T_{1}, T_{2}\right)=\lambda \sigma\left(t, T_{1}, T_{2}\right) F\left(t, T_{1}, T_{2}\right) d t+\sigma\left(t, T_{1}, T_{2}\right) F\left(t, T_{1}, T_{2}\right) d W(t)$ where $\sigma\left(t, T_{1}, T_{2}\right)$ is the volatility function, $\lambda$ takes account of the drift term under the physical probability measure, $W(t)$ is a standard Brownian motion. The volatility function should capture both the maturity effect and the seasonal effect.

\section{B. Electricity Options Contracts}

The widely traded electricity options contracts are options written on the above discussed electricity swaps contracts rather than plain vanilla options written on spot electricity. Electricity options belong to average type path-dependent derivatives and are more suitably called electricity swaptions. Like the way we discuss electricity swaps, the market reality is worth to be investigated. At Nord Pool, European style swaptions are the most actively traded electricity options contracts. They are written on the nearest 2 quarters and 2 years swap contracts. The trading period is half a year for options written on quarter-swaps and two-year for options written on year-swaps. The expiry day of the option is the third Thursday in the month before delivery. Five strikes are set when an option series is initially listed for trade. In the US, PJM European style electricity swaptions are traded on NYMEX and the trading unit is one (NYMEX Division) PJM monthly electricity swap contracts. The trading period is the current year plus the next five calendar years. The expiry day is set as two business days prior to the underlying futures month. There are total of at least 61 strike prices for the same underlying monthly swap. The at-the-money strike price is nearest to the previous day's close of the underlying swap contract. Strike price boundaries are adjusted according to the futures price movements. At AEM in Australia, swaptions are traded both through OTC and also on SFE as quarterly contracts, up to 4 years in the future. Besides swaptions, caps ${ }^{2}$, floors, and collars are also commonly traded options at AEM.

We argue that a swaption written on an electricity swap is not equivalent to a portfolio of options written on single/instantaneous futures/forwards or written on spot electricity. This is because the decision made on whether to exercise a swaption is a one-time decision before the delivery of the underlying swap, while a portfolio of options implies a series of decisions made during the delivery period. The information sets available to option holders are different in these two scenarios.

The complexity of pricing models for electricity swaptions depends on the models used for underlying swaps. For a swap model using the indirect approach, the corresponding swaption model becomes complex. However, a swap model adopting the direct approach can lead to a tractable swaption model with a Black-Scholes type of formula as shown in [14].

\section{A GENERAL POWER CONTRACT PORTFOLIO OPTIMIZATION PROBLEM}

In a deregulated power market, individual generation company strives to optimize its portfolio to achieve profit maximization. At the same time, managing a power portfolio becomes a risky business because deregulation brings in market uncertainty as well. In order to hedge against market risks, various power derivative contracts have been developed, such as swaps and swaptions which are discussed in the previous section. Although the optimization objective remains unchanged, the innovation of supply instruments should be accommodated in portfolio components, and more sophisticated risk measures should be catered.

With regard to risk measures, variance is incapable of dealing with the asymmetrical profit/loss distribution of a power portfolio as recognized among researchers. VaR is a breakthrough to aggregate risk across an institution, which summarizes the worst loss over a target horizon that will not be exceeded with a given level of confidence [15]. However, VaR suffers the criticism that it is not subadditive. A coherent risk measure $\mathrm{CVaR}$ which is derived from $\mathrm{VaR}$ is adopted here to form the risk constraint.

We argue the horizon for a single period optimization problem should be chosen as one month. This is because monthly swaps and their corresponding swaptions are widely traded, and it is more critical for the generation company to consider monthly rather than yearly profit/loss in order to reserve enough capital to cover the exposed intermediate risks.

The case here is a power portfolio considered by a generation company, and this portfolio consists of various power supply contracts. The loss function of the portfolio is defined as $f(\omega, y)=-\omega^{T} y$, where $\omega$ is the decision vector

\footnotetext{
${ }^{2}$ The most widely traded options at AEM are not swaptions but caps.
} 
$\left(\omega_{1}, \omega_{2}, \ldots, \omega_{m}\right)$ representing the percentage of generation asset allocated among $\mathrm{m}$ supply contracts. The random vector $\mathrm{y}$ is the expected profit in each of these contracts. Let the density function of y be $p(\cdot)$. Given a decision $\omega$, the probability of $f(\omega, y)$ not exceeding a threshold $\alpha$ is represented as $\Psi(\omega, \alpha)=\int_{f(\omega, y) \leq \alpha} p(y) d y$.

Given a confidence level $\beta$ and a fixed $\omega$, the portfolio $\mathrm{VaR}$ is defined as

$$
\operatorname{VaR}_{\beta}(\omega)=\min \{\alpha \in R: \Psi(\omega, \alpha) \geq \beta\}
$$

The $C V a R_{\beta}(\omega)$ is defined as the expected value of loss that exceeds $\operatorname{VaR}_{\beta}(\omega)$

$$
\operatorname{CVaR}_{\beta}(\omega)=\frac{1}{1-\beta} \int_{f(\omega, y) \geq \operatorname{VaR} R_{\beta}(\omega)} f(\omega, y) p(y) d y
$$

Rockafellar and Uryasev in [16], [17] defined a function $F_{\beta}(\omega, \alpha)$ to solve the above $\mathrm{CVaR}$

$$
F_{\beta}(\omega, \alpha)=\alpha+\frac{1}{1-\beta} \int_{y \in R^{m}}[f(\omega, y)-\alpha]^{+} p(y) d y
$$

where $[t]^{+}=\max \{t, 0\}$.

Then, we have $C \operatorname{VaR}_{\beta}(\omega)=\min _{\alpha} F_{\beta}(\omega, \alpha)$

The discrete version to approximate $F_{\beta}(\omega, \alpha)$ with totally $\mathrm{N}$ samples could be chosen as

$$
F_{\beta}(\omega, \alpha) \square \alpha+\frac{1}{N(1-\beta)} \sum_{k=1}^{N}\left[f\left(\omega, y_{k}\right)-\alpha\right]^{+}
$$

By introducing an auxiliary variable $z_{k}$ for $\mathrm{k}=1,2, \ldots, \mathrm{N}$, the above $F_{\beta}(\omega, \alpha)$ could be written as

$$
\left\{\begin{array}{l}
F_{\beta}(\omega, \alpha)=\alpha+\frac{1}{N(1-\beta)} \sum_{k=1}^{N} z_{k} \\
z_{k} \geq 0, \text { and } \omega^{T} y_{k}+\alpha+z_{k} \geq 0
\end{array}\right.
$$

The optimization problem is formed as maximizing profit with risk as the constraint. Recall the way that $\mathrm{CVaR}$ is defined, i.e. $\operatorname{CVaR}_{\beta}(\omega)=\min _{\alpha} F_{\beta}(\omega, \alpha)$, this optimization problem is a bi-level optimization problem as

$$
\begin{aligned}
\max _{\omega} & -f(\omega, y) \\
\text { s.t. } & \min _{\alpha} F_{\beta}(\omega, \alpha) \leq V
\end{aligned}
$$

where $\mathrm{V}$ is the risk tolerance level specified by the GenCo.

This in our case could be further written as

$$
\begin{aligned}
& \max _{\omega} \omega_{i}\left(\frac{1}{N} \sum_{k=1}^{N}\left(y_{i}\right)_{k}\right) \\
& \text { s.t. } \sum_{i=1}^{m} \omega_{i}=1 \\
& \omega_{i} \geq 0, i=1,2, \ldots, m \\
& F\left(\alpha^{*}, z^{*}\right) \leq V, \text { where }\left(\alpha^{*}, z^{*}\right) \text { is the solution of } \\
&\left\{\min _{\alpha, z} F_{\beta}(\omega, \alpha)=\alpha+\frac{1}{N(1-\beta)} \sum_{k=1}^{N} z_{k}\right. \\
& \text { s.t. } z_{k} \geq 0, \sum_{i=1}^{2} \omega_{i}\left(y_{i}\right)_{k}+\alpha+z_{k} \geq 0, k=1,2, \ldots, N
\end{aligned}
$$

As proved in [18], if the above constraint $\alpha+\frac{1}{N(1-\beta)} \sum_{k=1}^{N} z_{k} \leq V$ is active and the corresponding multiplier of the constraint is not equal to zero, the above bilevel optimization model is equivalent to a single layer linear optimization model as below:

$$
\min _{(\alpha, z, \omega)}\left[-\frac{1}{N} \sum_{k=1}^{N} \omega^{T} \mathbf{y}_{k}\right]
$$

s.t.

$$
z_{k} \geq 0, \text { and }\left(\omega^{T} \mathbf{y}_{k}+\alpha+z_{k}\right) \geq 0, k=1, \ldots, N
$$

$\sum_{i=1}^{m} \omega_{i}=1$

$$
\alpha+\frac{1}{N(1-\beta)} \sum_{k=1}^{N} z_{k} \leq V
$$

\section{NUMERICAL EXAMPLE}

A generation company normally holds the short position of European call swaptions and the long position of European put swaptions. Whether the option will be exercised depends primarily on the trading price of the underlying swap on the expiry day of the option. Take the European call swaption as an example. If it is exercised by the counterparty, the generation company will have the obligation to sell a swap contract to this counterparty with the strike price and the amount of power specified in this swaption. If it is abandoned, the generation company will need to either sell this amount of power as swaps in the days left before the delivery month or sell this amount in the spot market in the delivery period. Compared with the power volume traded in the spot market and the swap market, the amount of power covered by power swaptions is relatively small. In addition, the decision made on a swaption will lead to the transformation of the power covered in this swaption either to the monthly swap contract or to the spot market. Hence, the primary decision of portfolio asset allocation should be between the swap contract and the spot market.

In order to emphasize the core issue, the following numerical study assumes the decision has been made on the 
swaption. Data are referenced to the Nord Pool database. The model adopted for swaps pricing is a market model from [14], and the model for spot pricing is a Geometric Mean Reversion (GMR) model from [19]. For the spot price model, the longterm mean of the hourly price is set as the average of Nord Pool system prices of April in recent years. The generation variable cost is set as $20 \mathrm{EUR} / \mathrm{MWh}$, and the depreciated monthly fixed cost is 8500 EUR/MW-month. The volatility factor is set as 2 according the real trading data. Other settings follow [19]. Figure 2 shows the histogram of a monthly profit in the spot market obtained through a 90-time Monte-Carlo simulation. The swap model and corresponding parameter settings follow [14]. The costs are set the same as in the spot profit model, and the initial value of the price process is set as $30 \mathrm{EUR} / \mathrm{MWh}$. We consider the uncertainty stem from the possibility to enter the swap contract at different time. Figure 3 shows the histogram of the monthly profit from the swap contract with the same number of samples as in the histogram of spot market.

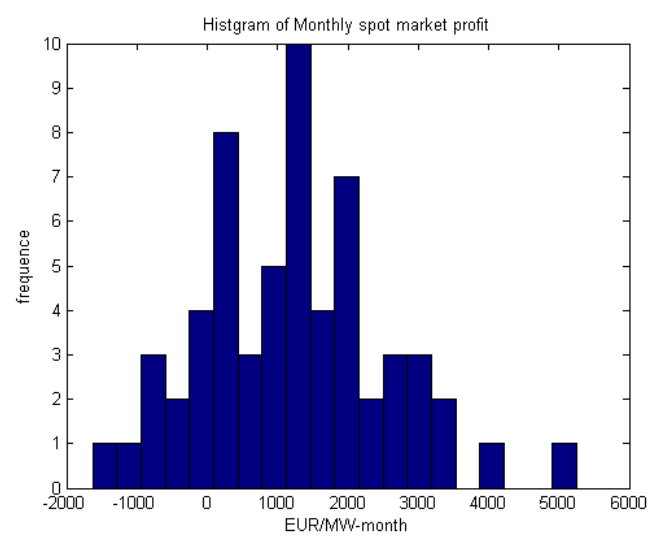

Figure 2 Histogram of monthly profit in the spot market

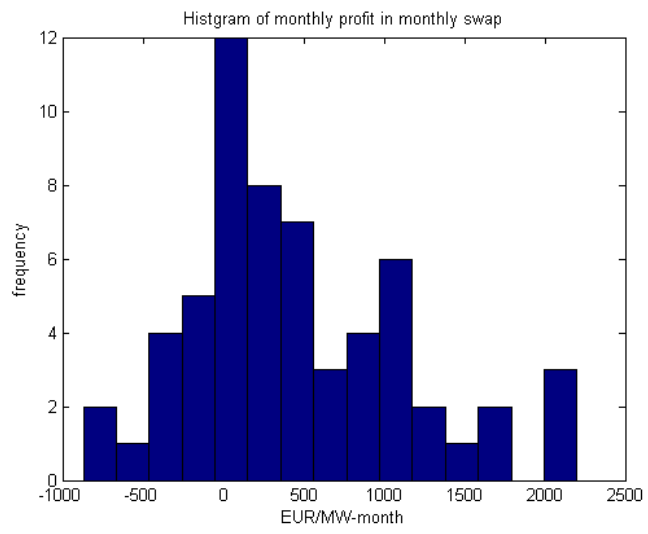

Figure 3 Histogram of monthly profit in the swap market

Through the above two histograms, we could see the spot market shows higher profitability and higher risk as well. In reality, a generation company secures certain amount of its revenue in the less volatile swap market, and speculate the rest of its capacity in the spot market.

The linear programming optimization model discussed in the previous section is used to solve this allocation problem.
Figure 4 shows the allocation percentage between these two markets as a function of CVaR risk levels set in the model. Figure 5 shows the optimized profit also as a function of risk values with a $95 \%$ confidence level.

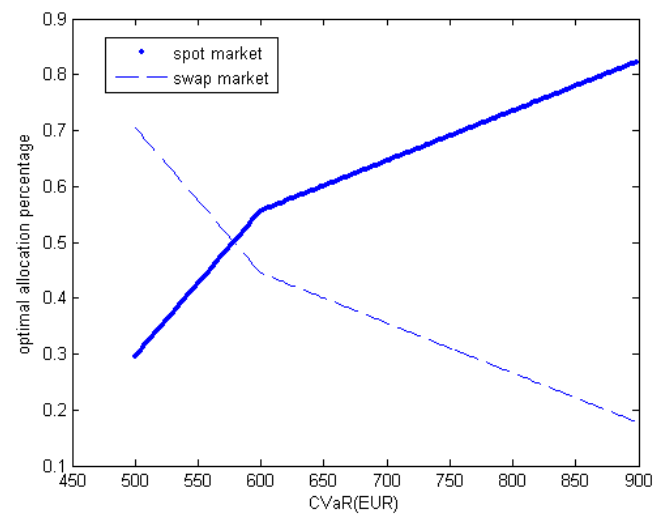

Figure 4 Percentage allocations between spot and swap

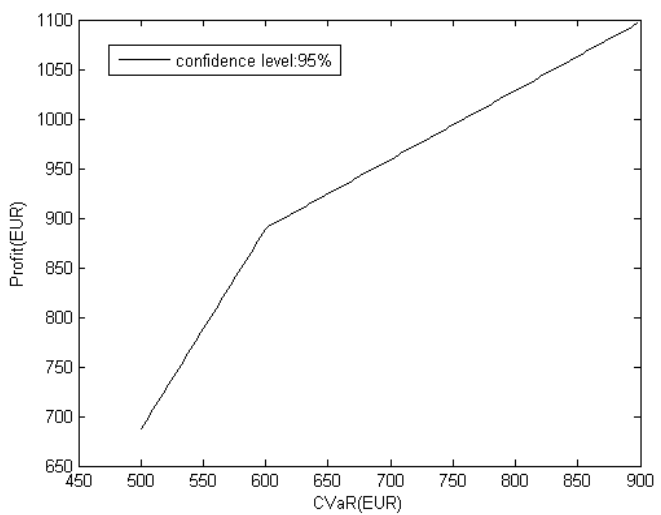

Figure 5 Optimized profit at different risk levels with 95\% confidence

The results are consistent with intuition. With looser risk constraints, the allocation gives more weight to the spot market, and the expected profit also increases.

\section{CONCLUSION}

An engineering thought has driven us to substitute those hypothetical contracts in a conventional power portfolio with most liquidly traded contract products. Through investigation, we clarify that electricity forwards/futures contracts are swaps covering various delivery periods, and these swaps serve as the underlying of electricity options. Both the trading reality and the proposed pricing models of these contracts are also discussed. Taking the perspective from a generation company, a portfolio optimization problem is formulated with profit maximization as its objective and $\mathrm{CVaR}$ as risk constraint. The risk hedging role provided by these path-dependent power derivatives is unique compared with in other financial markets. Last but not least, in order to cope with the complexity brought by multiple exotic contracts and by market uncertainties, the state-of-art development of modern portfolio theory should be effectively applied. 


\section{REFERENCES}

[1] Thorsten Hens, Advanced Portfolio Theory, Lecture notes, October 2004, Norwegian School of Economics and Business Administration.

[2] Jun Xu, Peter B. Luh, et. al, 2006. Power Portfolio Optimization in Deregulated Electricity Markets with Risk Management, IEEE Transactions on Power Systems, Vol. 21, No. 4, pp1653-1662.

[3] Paul R. Kleindorfer, and Lide Li, 2003. Multi-Period VaR-Constrained Portfolio Optimization with Applications to the Electric Power Sector, Energy Journal, 26(1), pp1-26.

[4] Andreas Eichhorn, and Werner Romisch, 2006. Mean-risk Optimization Models for Electricity Portfolio Management, Proceedings of Probabilistic Methods Applied to Power Systems, Stockholm (Sweden).

[5] Gustaf Unger, 2002. Hedging Strategy and Electricity Contract Engineering, $\mathrm{PhD}$ thesis, Swiss Federal Institute of Technology Zurich.

[6] Lucia, J. J. and Schwartz, E. S., 2002. Electricity Prices and Power Derivatives: Evidence from the Nordic Power Exchange, Review of Derivatives Research, 5, p5-20.

[7] Wilkens, S. and Wimschulte, J., 2007. The Pricing of Electricity Futures: Evidence from the European Energy Exchange, The Journal of Futures Markets, Vol. 27, No. 4, p387-410.

[8] Koekebakker, S. and Ollmar, F., 2005. Forward Curve Dynamics in the Nordic Electricity Market, Managerial Finance, Volume 31, Number 6.

[9] Audet, N., Heiskanen, P., Keppo, J. and Vehvilainen, I., 2004. Modeling Electricity Forward Curve Dynamics in the Nordic Market, Modeling Prices in Competitive Electricity Markets, John Wiley \& Sons Inc, p251265.

[10] Borovkova, S. and Geman, H., 2007. Seasonal and Stochastic Effects in Commodity Forward Curves, Review of Derivatives Research, 9, p167186.

[11] Heath D., Jarrow R., and Morton A., 1992. Bond Pricing and the Term Structure of Interest Rates: A New Methodology for Contingent Claim Valuation, Econometrica, 60, pp77-105.

[12] Jarrow R., 1997. The HJM Model: Its Past, Present, and Future, Keynote Address IAFE Conference.

[13] Brace A., Gatarek D., and Musiela M., 1997. The Market Model of Interest Rate Dynamics, Mathematical Finance, Vol. 7, No. 2, pp127147.

[14] Benth F. E., and Koekebakker S., 2008. Stochastic Modeling of Financial Electricity Contracts, Energy Economics, 30, pp1116-1157.

[15] Philippe Jorion, Value at Risk: The New Benchmark for Managing Financial Risk, 2007, Third Edition, McGraw Hill.

[16] Rockafellar R. T. and Uryasev S., 2000. Optimization of Conditional Value-at-risk, The Journal of Risk, Vol. 2, No. 3, pp21-41.

[17] Rockafellar R. T. and Uryasev S., 2002. Conditional Value-at-risk for General Loss Distributions, Journal of Banking and Finance, 26, pp1443-1471.

[18] Tong X., Wu F. F., Qi L., 2009. Worst-case CVaR based portfolio optimization models with applications to scenario planning. Optimization Methods and Software, Vol. 24, Issue 6, pp933-958.

[19] Wu F. F., Su J. F., Zhou H., Hou Y. H., 2008. Valuation of Generator Profit from Spot Market: Simulation Approach, submitted to IEEE Trans. on Power Systems.

\section{BIOGRAPHIES}

Yi Sun received his B.Eng. degree from North China Electric Power University, China in 2005, and graduated with a M.S. from the University of Bath, UK in 2006. Currently he is a Ph.D. candidate with the Centre for Electrical Energy Systems, University of Hong Kong, Hong Kong. His research interests include power investment planning and power industry restructuring.

Felix F. Wu is the Philip Wong Wilson Wong Professor in Electrical Engineering at the University of Hong Kong, Hong Kong, where he served as Pro Vice Chancellor (Vice President) from 1997 to 2001. He is also a Professor Emeritus at the University of California, Berkeley, where he has been on the Faculty since 1974.
Hui Zhou received his B.Eng. degree and Ph.D. degree both from Huazhong University of Science and Technology, China, in 2002 and 2009 respectively. He is currently with Zhejiang Electric Power Coporation, State Grid, China He was with the Centre for Electrical Energy Systems, University of Hong Kong, Hong Kong when he participated in this work. 